\title{
Wavelength dependence of the damage threshold of inorganic materials under extreme-ultraviolet free-electron-laser irradiation
}

\author{
S. P. Hau-Riege, ${ }^{1, a)}$ R. A. London, ${ }^{1}$ R. M. Bionta, ${ }^{1}$ D. Ryutov, ${ }^{1}$ R. Soufli, ${ }^{1}$ S. Bajt, ${ }^{1}$ \\ M. A. McKernan, ${ }^{1}$ S. L. Baker, ${ }^{1}$ J. Krzywinski, ${ }^{2}$ R. Sobierajski, ${ }^{3}$ R. Nietubyc, ${ }^{3}$ \\ D. Klinger, ${ }^{3}$ J. B. Pelka, ${ }^{3}$ M. Jurek, ${ }^{3}$ L. Juha, ${ }^{4}$ J. Chalupský, ${ }^{4}$ J. Cihelka, ${ }^{4}$ V. Hájková, ${ }^{4}$ \\ A. Velyhan, ${ }^{4}$ J. Krása, ${ }^{4}$ K. Tiedtke, ${ }^{5}$ S. Toleikis, ${ }^{5}$ H. Wabnitz, ${ }^{5}$ M. Bergh, ${ }^{6}$ \\ C. Caleman, ${ }^{6}$ and N. Timneanu ${ }^{6}$ \\ ${ }^{1}$ Lawrence Livermore National Laboratory, Livermore, California 94550, USA \\ ${ }^{2}$ SLAC National Accelerator Laboratory, 2575 Sand Hill Road, Menlo Park, California 94025, USA \\ ${ }^{3}$ Institute of Physics PAS, Al. Lotników 32/46, PL-02-668 Warsaw, Poland \\ ${ }^{4}$ Institute of Physics AS CR, Na Slovance 2, 18221 Prague 8, Czech Republic \\ ${ }^{5}$ Deutsches Elektronen-Synchrotron DESY, Notkestrasse 85, 22607 Hamburg, Germany \\ ${ }^{6}$ Department of Cell and Molecular Biology, Biomedical Centre, Uppsala University, P.O. Box 596, \\ SE-75124 Uppsala, Sweden
}

(Received 27 March 2009; accepted 13 August 2009; published online 14 September 2009)

\begin{abstract}
We exposed bulk $\mathrm{SiC}$ and films of $\mathrm{SiC}$ and $\mathrm{B}_{4} \mathrm{C}$ to single 25 fs long free-electron-laser pulses with wavelengths between 13.5 and $32 \mathrm{~nm}$. The materials are candidates for x-ray free-electron laser optics. We found that the threshold for surface-damage of the bulk $\mathrm{SiC}$ samples exceeds the fluence required for thermal melting at all wavelengths. The damage threshold of the film sample shows a strong wavelength dependence. For wavelengths of 13.5 and $21.7 \mathrm{~nm}$, the damage threshold is equal to or exceeds the melting threshold, whereas at $32 \mathrm{~nm}$ the damage threshold falls below the melting threshold. (c) 2009 American Institute of Physics. [doi:10.1063/1.3216845]
\end{abstract}

Free-electron lasers (FELs) produce tunable, coherent, and high-power radiation and have recently been extended to short wavelengths. The FEL in Hamburg (FLASH) produces 25 fs long pulses of more than $10^{12}$ photons in the extremeultraviolet (EUV) range between 60 and $6 \mathrm{~nm}$. The Linac Coherent Light Source (LCLS) FEL is scheduled to deliver first light this year. ${ }^{2}$ It will produce 200 fs X-ray pulses with wavelengths between 1.5 and $0.15 \mathrm{~nm}$. The LCLS will be followed by facilities in Germany ${ }^{3}$ and Japan. ${ }^{4}$

X-ray FELs will enable unique ultrafast scientific research. At the same time, their unique output characteristics put severe requirements on the optics used to guide and shape the x-ray pulses, and the detectors used to characterize them. To avoid damage, various X-ray FEL-material interaction models, damage mechanisms, and optics design guidelines have been suggested. ${ }^{5-10}$ Surface melting is an important physical mechanism since it usually leads to and often sets the threshold for damage. Materials with low atomic number, $Z$, and high melting points are expected to exhibit the highest damage resistance since they absorb less light per unit mass and are mechanically stable. A definitive experimental verification of these models has not been performed since appropriate light sources are not yet available. Instead, existing light sources have been used to test the models by emulating the effect of $x$-ray FEL radiation, ${ }^{11,12}$ but they are operated typically at wavelengths longer than $32 \mathrm{~nm}$, making extrapolation to x-ray FEL conditions questionable. In this paper we determine the robustness of optical materials that will be used at LCLS, at wavelengths as short as $13.5 \mathrm{~nm}$ at FLASH. This wavelength range is substantially closer to the $\mathrm{X}$-ray FEL range than in previous work. Also, we compared bulk materials with thin films and found substantial differences in the damage resistance, suggesting that mechanical

${ }^{a)}$ Electronic mail: hauriege1@1lnl.gov. properties and stoichiometry determined by fabrication methodology have a strong effect on the damage resistance.

We studied different low $Z$ materials that are candidates for x-ray FEL optics: (i) SiC slabs fabricated by chemicalvapor deposition with an average grain size of $7.5 \mu \mathrm{m}$, (ii) $1 \mu \mathrm{m}$ thick amorphous $\mathrm{SiC}$ films, and (iii) $1 \mu \mathrm{m}$ thick amorphous $\mathrm{B}_{4} \mathrm{C}$ films. ${ }^{13}$ The films were deposited with planar dc-magnetron sputtering systems. ${ }^{14}$ The deposition system used for the $\mathrm{B}_{4} \mathrm{C}$ films is also being used for the deposition of the coatings on the LCLS x-ray mirrors. ${ }^{15}$ In cases (ii) and (iii) the substrates were (100) $\mathrm{Si}$ wafers. The $\mathrm{B}_{4} \mathrm{C}$ films deposited under regular conditions had high compressive stress $(>2 \mathrm{GPa})$, which led to delamination from the substrate. We increased the $\mathrm{B}_{4} \mathrm{C}$ deposition pressure to reduce the stress (to $0.9 \mathrm{GPa}$ ), at the expense of a slight increase in high-spatial-frequency roughness (HSFR). Grains appear to be separated by microvoids in some areas. Atomic force microscopy (AFM) measurements on other $\mathrm{B}_{4} \mathrm{C}$ films deposited under identical conditions, but with different thicknesses indicated that the grain size and resulting HSFR scale with film thickness. This type of morphology is consistent with a "zone 1/zone $T$ " structure model proposed by Thornton ${ }^{16}$ and is also consistent with data on sputtered $\mathrm{B}_{4} \mathrm{C}$ films presented in earlier literature. ${ }^{16-18} \mathrm{X}$-ray photoelectron spectroscopy on a $\mathrm{B}_{4} \mathrm{C}$ film aged for about 1 month indicated that the top $9 \mathrm{~nm}$ of the film is oxygen and carbon rich $(64 \%$ $\mathrm{B}, 22 \% \mathrm{C}$, and $13 \% \mathrm{O}$, atomic) with the oxygen and carbon concentrations rapidly diminishing with depth from the top surface. Rutherford backscattering (RBS) measurements across the entire $\mathrm{B}_{4} \mathrm{C}$ film thickness indicated atomic ratio of boron-to-carbon $=3.7$ (near perfectly stoichiometric), with $6 \%$ oxygen present, believed to come from the $\mathrm{B}_{4} \mathrm{C}$ sputtering target. Using the RBS measurements combined with scanning electron microscopy (SEM) thickness and EUV reflectance measurements, it was determined that the density of 
(a)

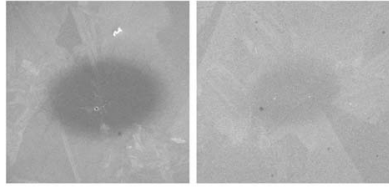

(b)

(c)
FIG. 1. Representative SEM images of bulk SiC exposed to the FLASH beam slightly above the damage threshold at wavelengths of $13.5,21.7$, and $32 \mathrm{~nm}$, respectively. The widths of the images are (a) $10.6 \mu \mathrm{m}$, (b) $25.1 \mu \mathrm{m}$, and (c) $24.5 \mu \mathrm{m}$.

the films is $2.28 \mathrm{~g} / \mathrm{cm}^{3}$ (about $90 \%$ of crystalline $\mathrm{B}_{4} \mathrm{C}$ ). The aforementioned properties are generally consistent with the properties of $\mathrm{B}_{4} \mathrm{C}$ films made using physical vapor deposition methods. RBS measurements on $\mathrm{SiC}$ films deposited under conditions similar to the $1 \mu \mathrm{m}$ thick SiC films used here indicated an atomic ratio of silicon-to-carbon of 0.98 (near-perfectly stoichiometric), with $5 \%$ oxygen. The density of the SiC films was determined to be $2.98 \mathrm{~g} / \mathrm{cm}^{3}$ (about 93\% of crystalline $\mathrm{SiC}$ ).

We exposed the different samples to single pulses of the focused FLASH beam under normal incidence. FLASH was operated at wavelengths of $32,21.7$, and $13.5 \mathrm{~nm}$. The pulse energies were up to $\sim 10 \mu \mathrm{J}$, and the pulse duration was $25 \pm 5$ fs. The FLASH beam was focused onto the sample using a grazing incidence ellipsoidal mirror to a Gaussian beam radius of 5 to $10 \mu \mathrm{m}$. The pulse energy was adjusted using a gas attenuator, and a gas monitor detector (GMD) was used to measure the energy of each pulse. ${ }^{19}$ In order to extract damage thresholds, we found it necessary to study the onset of surface modification at low pulse energies at or below $1 \mu \mathrm{J}$. Since the readout electronics of the GMD was not optimized for such low pulse energies we were only able to record the energy averaged over multiple pulses. Therefore, we used a statistical method to obtain the damage thresholds as for previous experiments. ${ }^{11}$ The statistical pulse energy distribution of a self-amplified-spontaneous-emission FEL follows a Gamma distribution with a shape parameter $M$ that describes the number of optical modes in the radiation source. ${ }^{20}$ Fitting a Gamma distribution to the measured highenergy (weakly attenuated) pulses, we found values for the shape parameter $M$ of $1.5,1.5$, and 3.5 for wavelengths of $13.5,21.7$, and $32 \mathrm{~nm}$, respectively. We exposed multiple spots (15-39) to pulses at a certain gas attenuator setting, corresponding to a certain average pulse energy. Using AFM, SEM, and white-light interference microscopy, ${ }^{21}$ we determined the fraction of the spots that are visibly undamaged. Finally, we determined the damage threshold fluence interval by mapping the undamaged and damaged spots onto the statistical pulse energy distribution.

We determined the Gaussian beam radii from the scaling of the measured damaged area as a function of the incoming pulse energy. ${ }^{22,23}$ We found radii of $4.8,8.1$, and $8.3 \mu \mathrm{m}$ at wavelengths of $13.5,21.7$, and $32 \mathrm{~nm}$, respectively.

We used white light interference microscopy ${ }^{21}$ to determine surface height profiles. Figure 1 shows representative profiles for bulk $\mathrm{SiC}$ exposed to the FLASH beam slightly above the damage threshold at wavelengths of 13.5, 21.7, and $32 \mathrm{~nm}$, respectively. This shows that the focal spot of the beam is well defined, allowing an accurate determination of the fluence. The grains visible in the images are of order the spot size. The three images look similar, indicating that the
TABLE I. Summary of the exposure runs and the extracted damage thresholds.

\begin{tabular}{|c|c|c|c|c|}
\hline Material & $\begin{array}{l}\text { Wavelength } \\
\text { (nm) }\end{array}$ & $\begin{array}{c}\text { Number exposures/ } \\
\text { damage sites }\end{array}$ & $\begin{array}{c}\text { Lower/upper } \\
\text { fluence } \\
\left(\mathrm{mJ} / \mathrm{cm}^{2}\right)\end{array}$ & $\begin{array}{l}\text { Damage } \\
\text { threshold } \\
\left(\mathrm{mJ} / \mathrm{cm}^{2}\right)\end{array}$ \\
\hline \multirow[t]{5}{*}{ SiC film } & \multirow[t]{2}{*}{13.5} & $35 / 2$ & $206 / 282$ & \multirow[t]{2}{*}{326} \\
\hline & & $35 / 6$ & $380 / 434$ & \\
\hline & \multirow[t]{2}{*}{21.7} & $39 / 14$ & $161 / 172$ & \multirow[t]{2}{*}{178} \\
\hline & & $15 / 4$ & $186 / 228$ & \\
\hline & 32 & $39 / 6$ & $33 / 36$ & 35 \\
\hline \multirow[t]{8}{*}{$\mathrm{B}_{4} \mathrm{C}$ film } & \multirow[t]{2}{*}{13.5} & $35 / 12$ & $323 / 350$ & \multirow[t]{2}{*}{348} \\
\hline & & $35 / 5$ & $333 / 388$ & \\
\hline & \multirow[t]{3}{*}{21.7} & $39 / 17$ & $96 / 102$ & \multirow[t]{3}{*}{83} \\
\hline & & $39 / 10$ & $72 / 79$ & \\
\hline & & $15 / 3$ & $142 / 181$ & \\
\hline & \multirow[t]{3}{*}{32} & $39 / 1$ & $18 / 23$ & \multirow[t]{3}{*}{18} \\
\hline & & $39 / 2$ & $22 / 26$ & \\
\hline & & $39 / 11$ & $10 / 10$ & \\
\hline \multirow[t]{5}{*}{ SiC bulk } & 13.5 & $35 / 21$ & $663 / 707$ & 685 \\
\hline & \multirow[t]{2}{*}{21.7} & $39 / 21$ & $321 / 339$ & \multirow[t]{2}{*}{298} \\
\hline & & $39 / 34$ & $254 / 277$ & \\
\hline & \multirow[t]{2}{*}{32} & $39 / 22$ & $75 / 77$ & \multirow[t]{2}{*}{141} \\
\hline & & $20 / 8$ & $54 / 58$ & \\
\hline
\end{tabular}

damage mechanism is likely to be the same. For the SiC film and the slab samples, we detected only craters, whereas for the $\mathrm{B}_{4} \mathrm{C}$ films we observed both extrusions, primarily at low pulse energies, and craters, primarily at large pulse energies. At a wavelength of $32 \mathrm{~nm}$, we detected only extrusions on $\mathrm{B}_{4} \mathrm{C}$ films for pulse fluences of up to $187 \mathrm{~mJ} / \mathrm{cm}^{2}$. At a wavelength of $21.7 \mathrm{~nm}$, we detected primarily extrusions up to $728 \mathrm{~mJ} / \mathrm{cm}^{2}$, and a few craters between 243 and $1213 \mathrm{~mJ} / \mathrm{cm}^{2}$ in the $\mathrm{B}_{4} \mathrm{C}$ films. Finally, at a wavelength of $13.5 \mathrm{~nm}$, we detected only extrusions in the $\mathrm{B}_{4} \mathrm{C}$ films up to $963 \mathrm{~mJ} / \mathrm{cm}^{2}$. The extrusions might be caused by a phase change in analogy to similar volume expansions studied in amorphous-carbon films. $^{24}$

We consider the surface damaged if we detect any surface modification by SEM, AFM, or white light interferometry. Table I lists the exposure runs that we performed along with the fraction of exposed sites identified as damaged. From this data, we can extract a range for the damage threshold using the statistical model for each exposure run, also listed in Table I. Finally, we take the damage threshold as the average of the midpoints of these ranges, weighted by the number of exposures per run.

We use the local dose as the basis for extrapolating FLASH results to the hard $\mathrm{x}$-ray regime. This concept is supported by the fact that in both cases the absorption mechanism is photoionization. The electrons then cascade down to energies of order $10 \mathrm{eV}$ before interacting with the lattice ions. In both cases, the timescale for heat conduction is much longer than the radiation pulse lengths, supporting the assumption that the absorbed energy stays confined and ends up as thermal energy before damage processes begin. The calculation of the dose from the incident fluence accounts for the particular absorption mechanisms that act in the two different wavelength regimes (i.e., $K$-shell, $L$-shell, etc.). For the FLASH case, the threshold surface dose is obtained by dividing the damage threshold fluence by the attenuation length. We assume that the optical properties of the materials do not change during the pulse $\mathrm{s}^{25}$ and that the materials are homogeneous, in which case the maximum dose occurs at the surface. Table II shows the attenuation 
TABLE II. Summary of damage threshold doses.

\begin{tabular}{lccrcr}
\hline \hline Wavelength (nm) & & 13.5 & 21.7 & 32 & Theor. \\
Attenuation length (nm) & Bulk SiC & 224 & 97 & 48 & \\
& SiC film & 241 & 105 & 52 & \\
& $\mathrm{~B}_{4}$ C film & 232 & 91 & 45 & \\
& $\mathrm{~B}_{4}$ C film & 130 & 54 & 28 & \\
Damage threshold (eV/atom) & Bulk SiC $^{\text {a }}$ & 2.0 & 2.0 & 1.9 & 1.00 \\
& SiC film & 0.9 & 1.2 & 0.5 & 1.00 \\
& $\mathrm{~B}_{4}$ C film & 0.8 & 0.5 & 0.2 & 0.77 \\
& $\mathrm{~B}_{4} \mathrm{C}$ film & 1.4 & 0.8 & 0.3 & 0.77 \\
\hline
\end{tabular}

${ }^{\mathrm{a}}$ We used the actual measured stoichiometry.

lengths and damage threshold doses for bulk $\mathrm{SiC}, \mathrm{SiC}$ films, and $\mathrm{B}_{4} \mathrm{C}$ films as a function of wavelength. We estimate the error in the damage threshold to be about $50 \%$ due to errors in the beam area, the energy measurement of the gas detector, and the small number of exposures per exposure series. Thermodynamic calculations show that crystalline $\mathrm{SiC}$ reaches the melting temperature at a dose of $0.63 \mathrm{eV} / \mathrm{atom}^{26}$ The heat of fusion is $0.37 \mathrm{eV} / \mathrm{atom},{ }^{26}$ so that a dose of 1.0 $\mathrm{eV} /$ atom is required to melt the material. Since the measured damage threshold is $2 \mathrm{eV} /$ atom, bulk $\mathrm{SiC}$ exhibits a remarkable resistance to single-pulse damage in the EUV regime. The rather weak wavelength dependence of the damage threshold dose over the range of 13.5-32 nm gives hope that the damage threshold at $1.5 \mathrm{~nm}$, (the long wavelength limit of LCLS) is similar.

Both the $\mathrm{SiC}$ and the $\mathrm{B}_{4} \mathrm{C}$ films show a strong wavelength dependence of the damage threshold dose. The threshold at $32 \mathrm{~nm}$ is particularly low, even when we correct for the actual stoichiometry of the $\mathrm{B}_{4} \mathrm{C}$ films. It is possible that the observed low damage thresholds are a manifestation of uncertainties in the absorption coefficients of sputtered $\mathrm{SiC}$ and $\mathrm{B}_{4} \mathrm{C}$ films containing oxygen, especially in the long wavelength regime. Crystalline $\mathrm{B}_{4} \mathrm{C}$ has a melting dose of $0.66 \mathrm{eV} /$ atom. Both the $\mathrm{SiC}$ and $\mathrm{B}_{4} \mathrm{C}$ film damage thresholds are at or above the melting thresholds of the corresponding crystalline materials at 13.5 and $21.7 \mathrm{~nm}$ wavelengths, but not as high as the bulk SiC samples. Since many grazing incidence optics for XFELs will use thin coatings, the lower damage thresholds doses found for thin films should be used as guidance for these facilities.

In summary, we measured the single-pulse damage resistance of candidate materials for LCLS optics at the FLASH facility, including bulk $\mathrm{SiC}$ and $\mathrm{SiC}$ and $\mathrm{B}_{4} \mathrm{C}$ films. We found that the damage thresholds at 13.5 and $21.7 \mathrm{~nm}$ wavelengths are above the melting thresholds, giving hope that a similar threshold or better can be expected at initial LCLS operation at a wavelength of $1.5 \mathrm{~nm}$. At $32 \mathrm{~nm}$, the damage thresholds of the films are below the melting threshold, which may be attributed to increased absorption.

This work performed under the auspices of the U.S. Department of Energy by Lawrence Livermore National Laboratory under Contract No. DE-AC52-07NA27344. This work was performed for the LCLS project at SLAC. This work was partially funded by the Czech Ministry of Education from the National Research Centers program Project Nos. LC510 and LC528, program INGO Grant No. LA08024, and by Academy of Sciences of the Czech Republic Grant Nos. Z10100523, IAA400100701, and KAN300100702.
${ }^{1}$ K. Tiedtke, A. Azima, N. von Bargen, L. Bittner, S. Bonfigt, S. Düsterer, B. Faatz, U. Frühling, M. Gensch, Ch. Gerth, N. Guerassimova, U. Hahn, T. Hans, M. Hesse, K. Honkavaar, U. Jastrow, P. Juranic, S. Kapitzki, B Keitel, T. Kracht, M. Kuhlmann, W. B. Li, M. Martins, T. Nuñez, E. Plönjes, H. Redlin, E. L. Saldin, E. A. Schneidmiller, J. R. Schneider, S. Schreiber, N. Stojanovic, F. Tavella, S. Toleikis, R. Treusch, H. Weigelt, M. Wellhöfer, H. Wabnitz, M. V. Yurkov, and J. Feldhaus, New J. Phys. 11, 023029 (2009).

${ }^{2}$ H. Winick, K. Bane, R. Boyce, J. Cobb, G. Loew, P. Morton, H. D. Nuhn, J. Paterson, P. Pianetta, T. Raubenheimer, C. Pellegrini, J. Rosenweiz, G. Ttravish, D. Prosnitz, E. T. Scharlemann, K. Halbach, K. J. Kim, R. Schlueter, M. Xie, R. Bonifacio, L. DeSalvo, and P. Pierini, Nucl. Instrum. Methods Phys. Res. A 347, 199 (1994).

${ }^{3}$ W. Decking, The European XFEL Project, in Brilliant Light in Life and Material Sciences (Springer, Netherlands, 2007).

${ }^{4}$ SCSS X-FEL Conceptional Design Report, edited by T. Tanaka and T. Shintake (Riken Harima Institute, Hyogo, Japan, 2005).

${ }^{5}$ R. Tatchyn, J. Arthur, R. Boyce, T. Cremer, A. Fasso, J. Montgomery, V. Vylet, D. Walz, R. Yotam, A. K. Freund, and M. R. Howells, Proc. SPIE 3154, 174 (1997).

${ }^{6}$ R. Bionta, LCLS Technical Note LCLS-TN-00-3, available at http://www-ssrl.slac.stanford.edu/lcls/technotes/.

${ }^{7}$ R. A. London, R. M. Bionta, R. O. Tatchyn, and S. Roesler, Proc. SPIE 4500, 51 (2001).

${ }^{8}$ A. Wootton, J. Arthur, T. Barbee, R. Bionta, R. London, H.-S. Park, D. Ryutov, E. Spiller, and R. Tatchyn, Proc. SPIE 4500, 113 (2001).

${ }^{9}$ D. D. Ryutov, Rev. Sci. Instrum. 74, 3722 (2003).

${ }^{10}$ M. Bergh, N. Timneanu, S. P. Hau-Riege, and H. A. Scott, Phys. Rev. E 77, 026404 (2008).

${ }^{11}$ S. P. Hau-Riege, R. A. London, R. M. Bionta, M. A. McKernan, S. L. Baker, J. Krzywinski, R. Sobierajski, R. Nietubyc, J. B. Pelka, M. Jurek, L. Juha, J. Chalupsky, J. Cihelka, V. Hajkova, A. Velyhan, J. Krasa, J. Kuba, K. Tiedtke, S. Toleikis, Th. Tschentscher, H. Wabnitz, M. Bergh, C. Caleman, K. Sokolowski-Tinten, N. Stojanovic, and U. Zastrau, Appl. Phys. Lett. 90, 173128 (2007).

${ }^{12}$ S. P. Hau-Riege, R. A. London, R. M. Bionta, R. Soufli, D. Ryutov, M. Shirk, S. L. Baker, P. M. Smith, and P. Nataraj, Appl. Phys. Lett. 93, 201105 (2008).

${ }^{13} \mathrm{~B}_{4} \mathrm{C}$ is the nominal stoichiometry.

${ }^{14}$ R. Soufli, A. L. Aquila, F. Salmassi, M. Fernández-Perea, and E. M. Gullikson, Appl. Opt. 47, 4633 (2008).

${ }^{15}$ R. Soufli, S. L. Baker, J. C. Robinson, E. M. Gullikson, T. J. McCarville, M. J. Pivovaroff, P. Stefan, S. P. Hau-Riege, and R. Bionta, Proc. SPIE 7361, 73610U (2009).

${ }^{16}$ J. A. Thornton, J. Vac. Sci. Technol. A 4, 3059 (1986).

${ }^{17}$ T. Eckardt, K. Bewilogua, G. van der Kolk, T. Hurkmans, T. Trinh, and W. Fleischer, Surf. Coat. Technol. 126, 69 (2000).

${ }^{18}$ Z. Han, G. Li, J. Tian, and M. Gu, Mater. Lett. 57, 899 (2002).

${ }^{19}$ K. Tiedtke, J. Feldhaus, U. Hahn, U. Jastrow, T. Nunez, T. Tschentscher, S. V. Bobashev, A. A. Sorokin, J. B. Hastings, S. Möller, L. Cibik, A Gottwald, A. Hoehl, U. Kroth, M. Krumrey, H. Schöppe, G. Ulm, and M. Richter, J. Appl. Phys. 103, 094511 (2008).

${ }^{20}$ E. L. Saldin, A. E. Schneidmiller, and M. V. Yurkov, The Physics of Free Electron Lasers (Springer, Heidelberg, 2000).

${ }^{21}$ We used the ZYGO white light interferometer fabricated by ZYGO Corp., Middlefield, CT

${ }^{22}$ J. M. Liu, Opt. Lett. 7, 196 (1982).

${ }^{23}$ J. Chalupsky, L. Juha, J. Kuba, V. Hajkova, J. Cihelka, P. Homer, M. Kozlova, T. Mocek, J. Polan, B. Rus, J. Krzywinsky, R. Sobierajski, H. Wabnitz, J. Feldhaus, and K. Tiedtke, Proc. SPIE 6586, 65860S (2007).

${ }^{24}$ L. Juha, M. Bittner, M. De Grazia, J. Feldhaus, J. Gaudin, S. Guizard, S. Jacobi, M. Kozlová, J. Krása, J. Krzywinski, H. Merdji, C. Michaelsen, T. Mocek, R. Nietubyc, M. Jurek, J. Polan, A. R. Präg, B. Rus, R. Sobierajski, B. Steeg-Keitel, M. Störmer, M. Stupka, V. Vorlíek, J. Wiesmann, and J. Wild, Proc. SPIE 5917, 59170F (2005).

${ }^{25}$ S. P. Hau-Riege, H.N. Chapman, J. Krzywinski, R. Sobierajski, S. Bajt, R.A. London, M. Bergh, C. Caleman, R. Nietubyc, L. Juha, J. Kuba, E. Spiller, S. Baker, R. Bionta, K. Sokolowski Tinten, N. Stojanovic, B. Kjornrattanawanich, E. Gullikson, E. Plönjes, S. Toleikis, and Th. Tschentscher, Phys. Rev. Lett. 98, 145502 (2007).

${ }^{26}$ NIST Chemistry WebBook, NIST Standard Reference Database Number 69, edited by P. J. Linstrom and W. G. Mallard (National Institute of Standards and Technology, Gaithersburg MD, 2005). 